\title{
PhysioArt: How We Made Physiology Study Enjoyable during Isolation Due to COVID-19
}

\author{
Beatriz Frederico Oliveira-Silveira1, Isabelly Cabral Souto', João Marcos Lima-Garcia1, \\ Valdir Andrade Braga ${ }^{1}$, Atalia Ferreira Lima Flôr ${ }^{1}$, Rayane Maria Pessoa de Souza1, \\ Francineide Fernandes-Costa ${ }^{1}$, Josimari M. DeSantana ${ }^{2}$, Josiane Campos Cruz ${ }^{1 *}$
}

${ }^{1}$ Biotechnology Center, Department of Biotechnology, Federal University of Paraiba, João Pessoa, Paraíba, Brazil ${ }^{2}$ Department of Physical Therapy, Graduate Program in Physiological Science and Graduate Program in Health Science, Federal University of Sergipe, Aracajú, Sergipe, Brazil

Email: *josianecruz@cbiotec.ufpb.br

How to cite this paper: Oliveira-Silveira, B. F., Souto, I. C., Lima-Garcia, J. M., Braga, V. A., Flôr, A. F. L., de Souza, R. M. P., Fernandes-Costa, F., DeSantana, J. M., \& Cruz, J. C. (2022). PhysioArt: How We Made Physiology Study Enjoyable during Isolation Due to COVID-19. Creative Education, 13, 283-295.

https://doi.org/10.4236/ce.2022.131017

Received: September 28, 2021

Accepted: January 25, 2022

Published: January 28, 2022

Copyright $\odot 2022$ by author(s) and Scientific Research Publishing Inc. This work is licensed under the Creative Commons Attribution International License (CC BY 4.0).

http://creativecommons.org/licenses/by/4.0/

\begin{abstract}
Many recent studies have alerted us to the health problems that students had to deal with during the COVID-19 isolation period. In this scenario, educators must consider new strategies to make online classes more attractive and enjoyable. We incorporated the PhysioArt project into our virtual classes. Here, we demonstrate how we made our online classes more pleasant and interesting through the interaction between physiology and art. We prepared an online multidisciplinary course, integrating anatomy, the history of science, and mythology, together with different art expressions. Thereafter, the students were invited to remotely recreate an artwork masterpiece based on the context of physiology. Our integrative classes and the PhysioArt project stimulated creativity and rationality, and it was an excellent strategy to motivate and increase student interest in learning physiology. This pedagogical online strategy, carried out during the coronavirus pandemic, has contributed to decreased social isolation and depression symptoms, as declared by many of the participants in our online class.
\end{abstract}

\section{Keywords}

Physiology, Art, Education, Pandemic, COVID-19

\section{Introduction}

Many graduate courses have successfully used art programs as a pedagogical tool in the teaching and learning process (Braverman, 2011; Flôr et al., 2020; Housen, 2002; Naghshineh et al., 2008; Perry et al., 2011; Shapiro et al., 2006). Literature, 
poetry, music, theater, and even museum visits have been used as successful pedagogical strategies (Flôr et al., 2020; Naghshineh et al., 2008; Perry et al., 2011). As an example, Naghshineh et al. (2008) offered a visual art course to medical and dental undergraduate students, stimulating them to describe details about an art masterpiece in a museum tour. According to the author, fine art analyses helped to develop visual skills and a clinically "active gaze" in the students, thereby helping them to perform patient anamnesis as they observed more details during interviews, which facilitated a more accurate diagnosis. In addition, exposure to fine art has helped these medical students to understand knowledge limitations akin to teaching them to be more tolerant of diagnosis uncertainty (Campbell, 2014; Naghshineh et al., 2008).

In our physiology course, we used art to increase the students' enthusiasm and desire to be involved in a subject within the discipline. In this project that began in 2015, we developed an activity that integrates art and physiology with our undergraduate students from the Biotechnology course at the Federal University of Paraiba, Brazil; it is called PhysioArt. In this project, students become artists by recreating a piece of artwork incorporating aspects of physiological concepts, as described in our recent publication (Flôr et al., 2020). PhysioArt activities have increased student commitment, as well as their interest in the discipline, in a more creative, agreeable, and enthusiastic atmosphere. Furthermore, art exposure and the active participation of students in our project have also contributed to the development of their creativity, critical thinking skills, self-pride, self-assurance, and self-esteem (Flôr et al., 2020).

Currently, in the COVID-19 pandemic phase, isolation during quarantine and/or lockdowns have reduced social interactions, and impacted friendships and co-cooperative networks. This led to the development of sadness, anxiety, depression symptoms, and even suicidal thoughts in many students (Chi et al., 2020; Elmer, Mepham, \& Stadtfeld, 2020; Kaparounaki et al., 2020; Odriozola-González, Planchuelo-Gómez, Irurtia, \& de Luis-García, 2020; Tang et al., 2020). In this scenario, professors need to urgently adopt pedagogical strategies to make online courses more attractive, interesting, and enjoyable. In light of this, we incorporated our PhysioArt project into our virtual physiology classes.

\section{Developing Our Online Integrative Physiology Course-A Report}

In 2020, considering distance learning, we offered online integrative physiology courses, including our PhysioArt project. Thus, we had two editions of our physiology online course: one teaching about the neuroscience of pain ( $n=32$ Ph.D. students from the Health Science Program of the Federal University of Sergipe, Brazil) and another edition teaching about cardiovascular physiology $(n=21$ participants). Under the stressful conditions imposed by the isolation of the COVID-19 pandemic, we explored physiology concepts that aided in the stimulation and commitment of our students to our online courses by integrating science history, art, and mythological symbolism. Our integrative classes were 
essential in offering students a more positive, beautiful, agreeable, and enjoyable atmosphere, thereby, contributing to the teaching and learning process. Furthermore, the PhysioArt activity enables online interaction between participants. All these interactions helped us to capture the students' attention and interest, which also helped in the teaching and learning process. In addition, these interactions between history, mythology, art, and physiology, as well as PhysioArt activities, have helped to stimulate the students' rationality and creativity, giving them support for their artwork reinterpretations. Thus, after our integrative classes, students were encouraged to participate in our PhysioArt activities. Our experience leads us to believe that our PhysioArt integrative course aids the teaching and learning process and, in many regards, helps to increase the interest and commitment/involvement of students, as well as relieve the stress induced by isolation. In the following text, we give some examples from our integrative physiology classes as well as examples from our PhysioArt online activities.

To provide some examples of our integrative online courses, here we highlight our online cardiovascular physiology classes, which were focused on heart anatomy and function, and pulmonary and systemic circulations. Interestingly, in our cardiovascular online course, we had 21 participants of different ages from different regions of Brazil, with different scholarly degrees. Thus, $35 \%$ of our participants were under 35 years old, $20 \%$ did not have a biological science background (some of them were from art education), $65 \%$ were undergraduate students (45\% from the biological science field), and 35\% were Ph.D. students ( $15 \%$ from the biological science field).

Here, we provide examples of how we explored art, science, history, and mythology in our virtual cardiovascular physiology course. We started our course by establishing an interesting and pleasant environment. To do this, we explored heart symbolism using the Greek myth "Isis and Osiris", described by Plutarco (46-120 AD). According to this ancient philosopher, the peach, for its heart-shaped aspect, was a fruit offered to the gods. By further exploring Greek myths, we showed an illustration from the "Egyptian book of the dead" and "Osiris Judgment", where according to Greek ancients, our personality was represented by the weight of our hearts. During their judgments, the hearts of the dead were compared on a scale against a feather from Ma'at, the goddess of truth. If the heart was lighter than the feather, then the soul of the dead was justified and he or she could pass on toward the bliss of the Field of Reeds (Figure 1(a)). These mythology stories do not contain physiological concepts about the cardiovascular system, but it is important, especially in this social distancing condition to captivate students' liking, attention, and interest. These mystic stories also helped us to establish a more creative environment, that helped our students in their artistic process to participate in the development of PhysioArt activity.

After establishing an interesting and likeable environment through heart symbolisms in our online classes, we then explored a brief history of the cardiovascular system using, for example, a picture from the "Mural of Mexican 


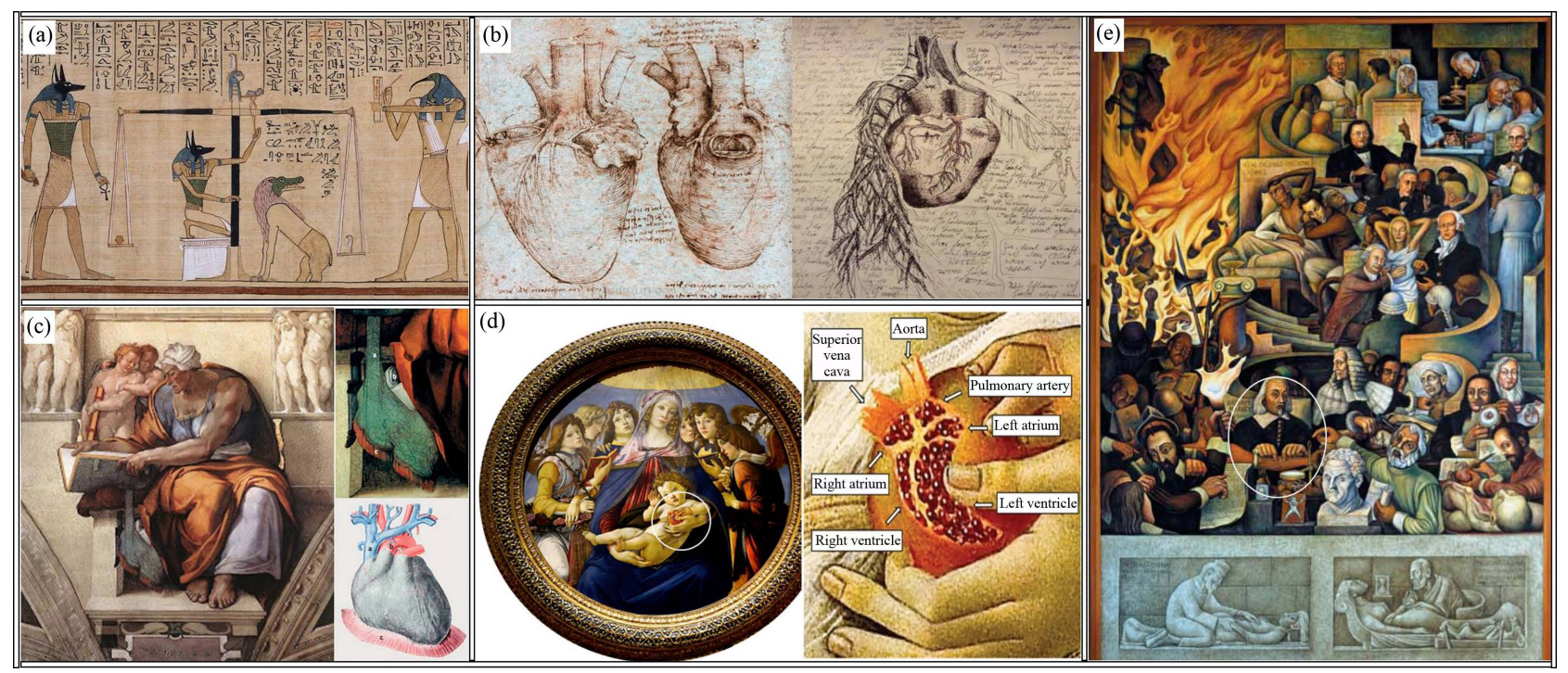

Figure 1. Panel (a): Hunefer's Judgement in the presence of Osiris from the Egyptian book of the dead. Panel (b): Circle-William Harvey, to his lower right Michel Servetus, left Claudius Galeno (bust), and Andreas Vesalius (dissecting a cadaver). Panel (c): Heart anatomy drawing and annotations by Leonardo da Vinci (1510, Collection Windsor Castle, United Kingdom). Panel (d): The Sistine chapel's "The Cumaean Sibyl” in the left side detail of the bag hanging below the book and above heart anatomy, highlighting the pericardium. Panel (e): On the right side is "Madonna of the Pomegranate" from Sandro Botticelli (1940, Galleria degli Uffizi), on the left side are details of the pomegranate and the hearts.

National Institute of Cardiology" painted by the Mexican artist Diego Rivera (Lomas, 2005). The mural highlights the names of philosophers and physicians who significantly contributed to the development of our knowledge about this system, such as Claudius Galeno, Andreas Vesalius, Michael Servetus, and William Harvey (Figure 1(b)) (Aird, 2011; Bestetti, Restini, \& Couto, 2014). The red and blue colors from Rivera's mural were probably inspired by William Harvey, who described the human blood circulation system in 1628 (Lomas, 2005) (Figure $1(\mathrm{e})$ ). In our brief history of the cardiovascular system, we highlighted the important contribution of the anatomist and physiologist William Harvey in understanding the circulation system and modern physiology. In our online classes we also explored some of his experiments and discoveries, as mentioned in the letter written by William Harvey himself (The Works of William Harvey, op. cit., letter.) to his friend Paul Slegel in 1651. In the letter, the physiologist described pulmonary circulation (Harvey \& Willis, 1847):

"Having tied the pulmonary artery, the pulmonary veins, and the aorta, in the body of a man who had been hanged, and then opened the left ventricle of the heart, we passed a tube through the vena cava into the right ventricle of the heart, and having, at the same time, attached an ox's bladder to the tube, in the same way as a clyster-bag is usually made, we filled it nearly full of warm water, and forcibly injected the fluid into the heart, so that the greater part of a pound of water was thrown into the right auricle and ventricle. The result was, that the right ventricle and auricle were enormously distended, but not a drop of water or of blood made its escape through the orifice in the left ventricle. The ligatures having been undone, the same tube was passed into the pulmonary artery, and a 
tight ligature having been put round it to prevent any reflux into a perforation in the left ventricle, so that a quantity of water, equal to that which was pressed from the bladder into the lungs at each effort, instantly escaped by the perforation mentioned. You may try this experiment as often as you please, the result you will still find to be as I have stated it".

The heart's anatomy is explained by anatomic figures from classical modern books, but it is also magnificently illustrated in drawings by Leonardo da Vinci (1452-1519) (Figure 1(b)), as well as in the hidden references (according to some authors) painted by Michelangelo Buonarroti in the Sistine Chapel ceiling frescoes; as in "The Cumaean SibyP" (Figure 1(c)) where in the green bag there is a reference to the heart, with the superior vena cava and aorta in the pericardium (Barreto \& Oliveira, 2004; Santos et al., 2013). In the Sibyl's right bent leg, there is an outline of the heart, and in the bend of the tunic is a reference to the right and left coronaries. While describing the heart's anatomy, we explored the portrait "Madonna Of Pomegranate" painted by Sandro Botticelli (1445-1510). In this portrait, Madonna is holding a peeled fruit in her left hand (Figure 1(d)). According to Lazzeri et al. (Lazzeri, Al-Mousawi, \& Nicoli, 2019), we can observe the heart's anatomy and cardiac chamber, resembling the atria, ventricles, and the main pulmonary trunk.

Subsequently, in our classes, cardiac automatism conceptions were briefly explored using the popular Brazilian song "Eu sei" (I know) composed by Arnaldo Antunes and interpreted by a famous Brazilian singer, Marisa Monte. Participants could listen to the music during the classes, in which one of the verses says, "my heart is an involuntary muscle and it beats for you" (Antunes \& Monte, 1991). In addition, interactions between heart function, the limbic system, and emotions were explored in accordance with Plato and Aristotle's philosophical conceptions that the heart is a source of four emotions: love, fear, anger, and pain (Gabbe, 2016). Furthermore, the animation "Brain Divided” by GG animation short (Haworth, Shik Song, \& Soo Song, 2016), was used by us to explain the interactions between the brain and heart, and how tachycardia may be induced in deeply emotional situations, such as when we fall in love.

At the end of our classes, a lot of heart references in pieces of artwork were used as additional illustrations to inspire and motivate the participants. These included "Icarus" (portfolio Jazz) from Henri Matisse (Matisse, 1947), "Two Fridas" from Frida Kahlo (Kahlo, 1939), "Anatomy of the heart" from Henrique Simonet y Lombardo (Simonet, 1890), and other references illustrated in the publication "Heartfelt images: learning cardiac science artistically" (Courneya, 2018). All participants agreed that the cardiovascular system studied in those interdisciplinary classes, exploring mythology, history, and art, had made the discipline much more enjoyable, thereby, increasing the participant's interest, attention, and involvement, thus improving the teaching and learning processes.

After our interdisciplinary classes on cardiovascular physiology, to break away from the impersonal atmosphere of online courses, we suggested that the participants bring their cups of coffee to our online class so that together we could en- 
joy our coffee and the class. It may have seemed like a meaningless activity, but considering the isolation and its effects on the students' mental health, this simple gesture makes the difference, creating a kinder, gentler, and friendlier atmosphere in our virtual class. It had substantial positive psychological effects under the condition of isolation, as noted by the participants of our coffee and PhysioArt sessions (Figure 2).

After our multidisciplinary physiology classes, students were asked to form groups of $3-4$ participants using the WhatsApp ${ }^{\mathrm{TM}}$ application. These groups always had a professor and a Ph.D. student involved in our art project, who were essential in answering questions and instructing the participants about PhysioArt activities. After that, participants attended a class that focused on our previous PhysioArt editions, which was important to provide examples of artwork interpretations in different physiology modules, as well as to inspire them.

We finished the course with a PhysioArt virtual exhibition, where each group had time to expound on their artwork interpretations, explain which part of the cardiovascular physiology they had explored in their work, and why they had chosen that artist and his/her specific portrait to be explored, as the correlation between their artwork interpretation and the meaning of the original painting.

At the beginning of the course, we were concerned about how the participants' artwork reinterpretations could be developed remotely, but they surprised us during the PhysioArt online exhibition. To give an example of how the participants could work in a group, even virtually, one of the PhysioArt groups made a painting as a tribute to Jean-Michel Basquiat's and Andy Warhol's work and friendship. First, the group decided that the right side of the heart would represent Basquiat's work and the left side, Warhol's. Then, they used drawing skills to compose a picture of an anatomic heart divided into four separate chambers that complement each other (Figure 3). Subsequently, each participant of the group was assigned one of the chambers, so they could interpret them in their own way. Finally, they used computer tools to unite all pieces together and make the final adjustments of the painting, which was called "Corona(ry)" alluding to the Coronavirus pandemic and the coronary vessels of the heart.

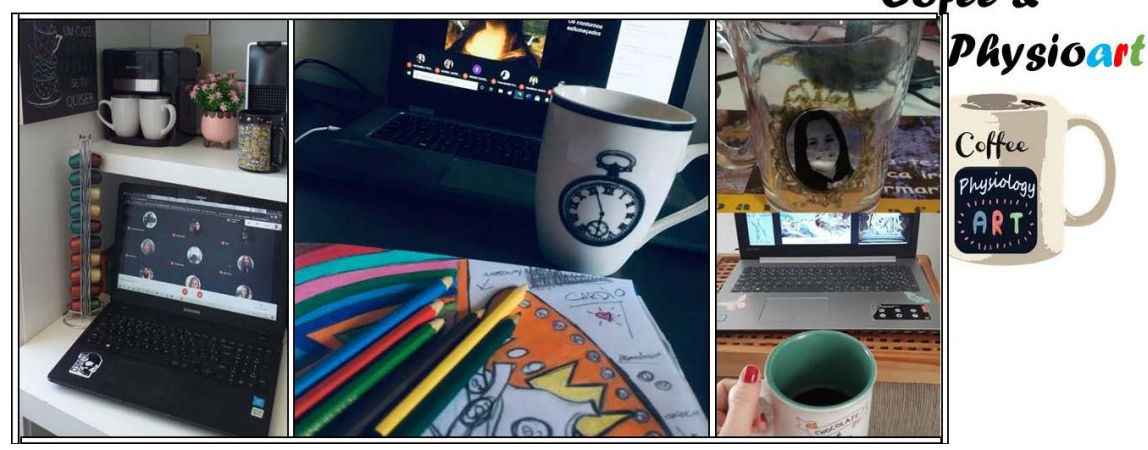

Figure 2. Photos of the participants in our online coffee \& PhysioArt class. 


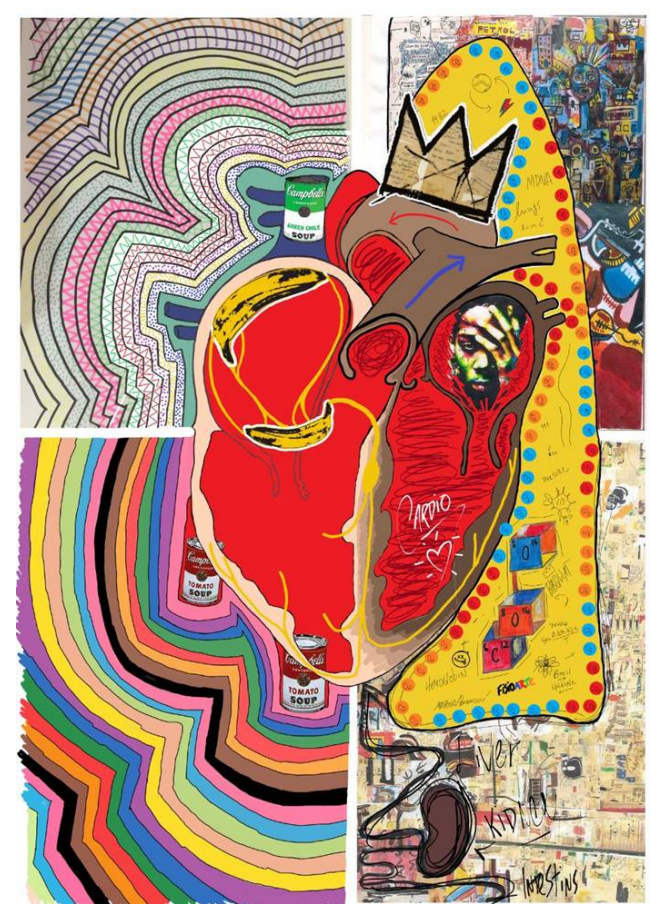

Figure 3. Corona(ry): The Artist is Absent. Right side: heart anatomy inspired by JeanMichel Basquiat, the details reference the interactions between heart, lung, and kidney functions. Left side: heart anatomy inspired in Andy Warhol artwork, the details reference the Campbell's Soup cans in the vessels, and the bananas represent the sinoatrial and atrioventricular nodes.

The process of making this collaborative painting over the internet (it is worth mentioning that none the students of this group knew each other before the course) was the performance that they called "The Artist is Absent". They chose that name for their performance to show an antithesis to a performance of a Serbian artist, Marina Abramovic, called "The Artist is Present," in which she was present 7 hours a day, 6 days a week for 3 whole months for an exhibition in the MOMA Museum (New York City) that centered on her career. During that time, she just sat and looked at the people who came to visit. This group said that Abramovic's performance was the exact opposite of what they had done. As a result of the pandemic, they could not be present for all parts of the process or for the exhibition of their work, at least physically, but that downside was overshadowed by their creativity and desire to create art.

In addition to these meaningful thoughts, they could still find space to incorporate several "easter eggs" of physiology, representing, for example, the shapes and colors of the vessels to cans of Campbell's Soup, and the sinoatrial and atrioventricular nodes with the banana from the cover of The Velvet Underground's album, because bananas are rich in potassium, which is important to induce electric potential in the heart's neurons. These were only two examples from the Andy Warhol side; on the right side, they represented Basquiat's work (Figure 3). They incorporated the circulatory system by showing other organs, and the relationship between the heart and the kidneys, for example, which 
through the Renin-Angiotensin-Aldosterone system, regulates blood pressure. In addition to those mentioned, many other easter eggs were found in the painting (Figure 3).

Another example of a virtual PhysioArt reinterpretation is shown in Figure 4. Collage art (PicsArt app) was used by participants to represent the heart's anatomy through Vincent van Gogh's artwork. The collage art was entitled "The van Gogh's heart in the Arles bedroom," which contains many symbolisms, engaging in a dialogue between the functional heart anatomy and van Gogh's paintings. Upon analyzing the collage artwork, in its background is the portrait "Bedroom in Arles" (Van Gogh, 1888) in which we can observe a respite and synchronic environment, representing the desire of the author after moving to Arles. This harmony represents the circulatory function of the heart, which is important for maintaining homeostasis in the body. The green window from "The Bedroom at Arles" at the entrance of the aorta representing the aortic valve, is half-open, which gives us a notion of aortic valve stenosis. Furthermore, on the left side of the heart, below the pulmonary artery, there is a fragment of "The Starry Night" (Van Gogh, 1889), the undulating waves in the horizon representing natural power, which was reinterpreted here as blood flow.

On the upper left side of the heart, there is an old man with his elbows on his knees and his head in his hand. Vincent van Gogh died two months after finishing this portrait “At Eternity's Gate" (Van Gogh, 1890a). The sad old man represents the interaction between the heart and emotions processed by the limbic system. "Vase with Irises Against a yellow background" (Van Gogh, 1890b), in the heart apex, suggests a word game with the paronymous "vases" of flowers and blood "vases". Finally, we can observe a portrait showing a heart on the bedroom wall, "The van Gogh's Heart".

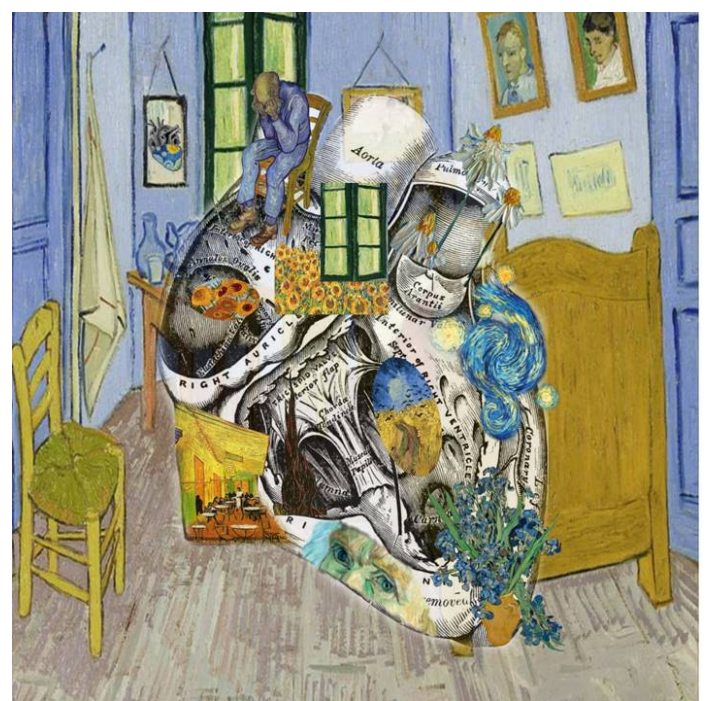

Figure 4. Systole and Diastole in Van Gogh's artwork. Art Collage (PicsArt app) of heart anatomy using fragments of van Gogh's artwork and having as a background the portrait "Bedroom in Arles" (first version) 1888, (Van Gogh Museum. Source: https://www.vangoghmuseum.nl/en/collection/s0047V1962). 
Figure 5 represents a reinterpretation of "Butterfly Apple" from the artist Vladimir Kush (Kush, 1978), which was made with colored pencils. The apple from the original portrait was replaced by a strawberry because it resembles a heart. Moreover, it is rich in flavonoids that have beneficial cardiovascular properties. In the strawberry, the pulp was painted to represent the cardiovascular valves during the systolic process. Additional artwork reinterpretations developed in our online cardiovascular PhysioArt course can be found on our Instagram page: fisio_arte (https://www.instagram.com/fisio_arte/).

At the end of our courses, participants voluntarily answered a survey (previously approved by the Institutional Education Committee) about our online courses. In Figure 6, we can observe that most students declared that our online integrative course and PhysioArt activity helped them to enjoy and learn physiology (Figure 6(a) and Figure 6(b)), as they experienced reduced stress from other online activities (Figure 6(c)). Furthermore, participants had declared that they felt anxious (50\%), depressed (19.5\%), sad and lonely (9\%), and $13.9 \%$ declared that they had felt two or more of these symptoms during the isolation period evoked by the coronavirus pandemic. Only $8.3 \%$ of our participants had declared having no changes in their mood or feelings (Figure 6(d)). Most of the participants declared that the art and physiology integrative course helped them to reduce depression symptoms brought on by this period of isolation (Figure $6(\mathrm{e}))$.

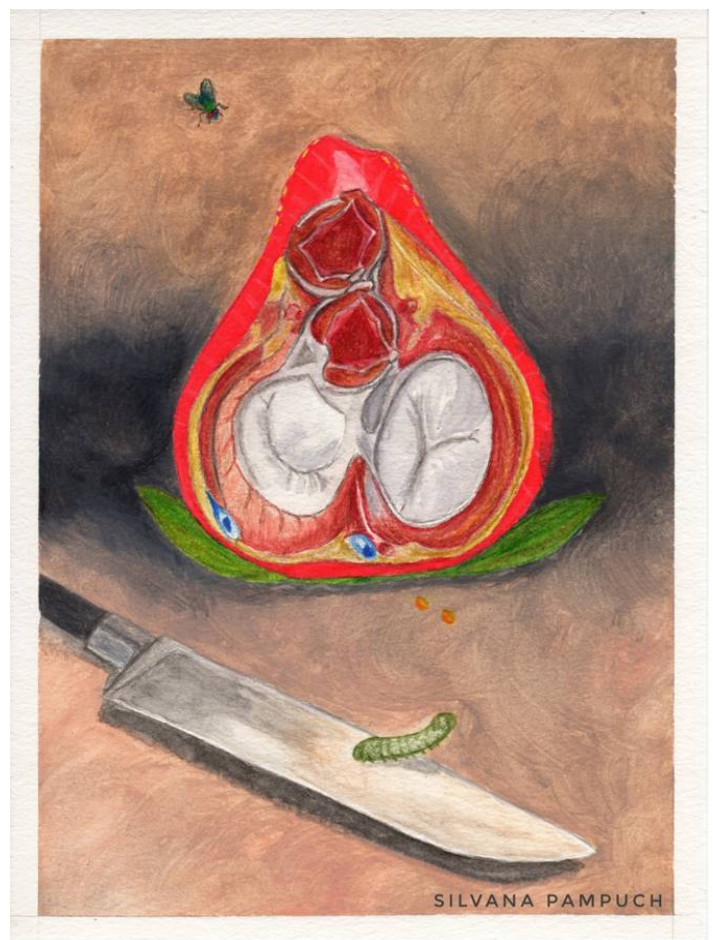

Figure 5. The heart valves. Artwork made with colored pencils, showing heart valves in a diastolic stage drawn in the pulp of a strawberry half. The fruit was chosen because it is rich in flavonoids, which have beneficial effects on heart function and has a shape similar to a symbolic heart. Source: https://vladimirkush.com/butterfly-apple. 


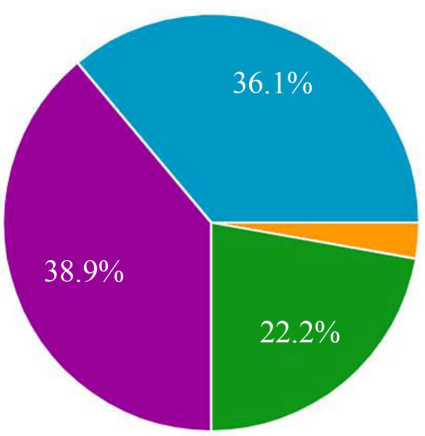

(a)

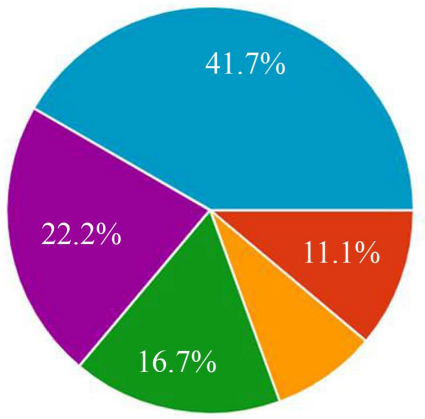

(b)

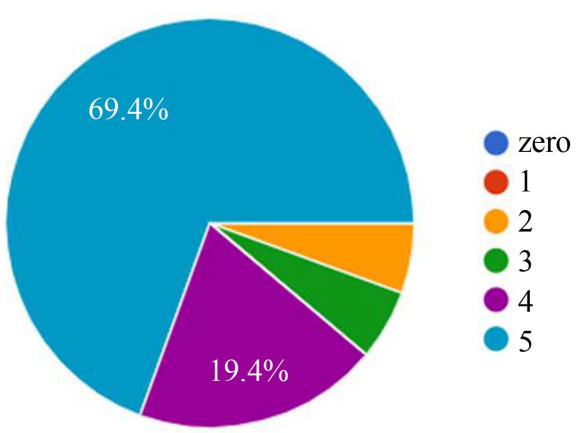

(c)

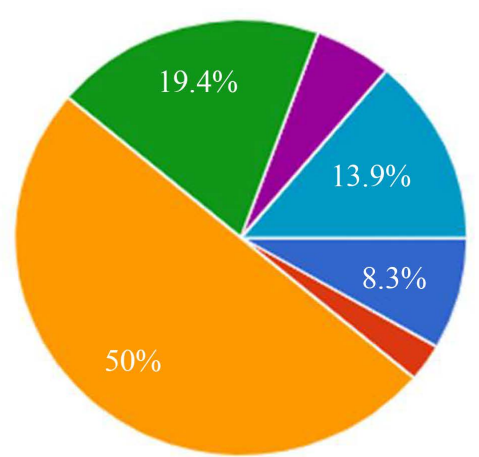

(d)

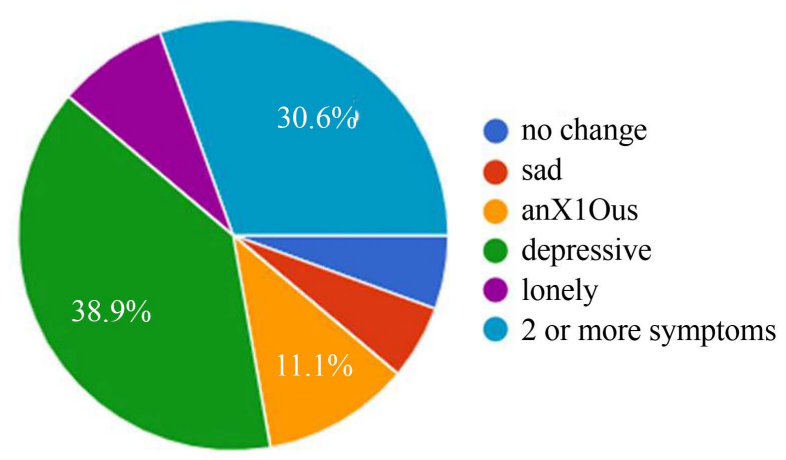

(e)

Figure 6. Panels (a)-(e): Survey answered (expressed in \%), showing the participant's perceptions $(\mathrm{n}=57)$ regarding the characteristics of our integrative art and physiology online courses. On a scale of zero to five: 0 (zero) = none and 5 (five) $=$ too much.

All the participants of our virtual course agreed that the interaction between physiology and art helped them to better understand physiological concepts, and motivated them to enjoy and study the discipline. Moreover, the PhysioArt activity has developed students' self-esteem, self-assurance, and pride, which is so crucial in the current isolation scenario caused by COVID-19.

\section{Discussion}

The virtual PhysioArt course allowed a new form of socialization, using cyberspace to promote empathy and cooperation. Moreover, many participants said that the virtual PhysioArt course helped them to diminish the isolation and boredom felt during the coronavirus pandemic. Thus, the PhysioArt project in its online version seems to be not only a pedagogical strategy to motivate students in our online classes, but also an aide for people to overcome the difficult times that we are living in, with the social isolation brought on by the coronavirus pandemic.

In addition, the interaction between art, mythology, and physiology made our online class more poetic-emotional, as related by many of the participants $(100 \%$ agreed that PhysioArt made the physiology class much more interesting and enjoyable). Considering that art is a powerful therapeutic tool that has helped many patients with mental disorders, including those with anxiety and depression (Chiang, Reid-Varley, \& Fan, 2019), we can say that the PhysioArt reinter- 
pretations have helped participants and students to have this direct contact with art and make them feel like "true artists", by stimulating their interaction, rationality, and creativity, thereby making them feel more proud and confident.

\section{Conclusion}

Thus, as many of the participants indicated, integrative physiology online classes and PhysioArt activities stimulated them to more enjoyably and creatively approach and learn physiology. It also helped them to avoid the boredom of virtual classes, as well as loneliness, anxiety, and depression symptoms aggravated by the COVID-19 isolation. As illustrated by this statement from one of the participants, "PhysioArt was an enriching experience, with many learnings. Besides all the creativity and sentimentality involved, the art contact provided by PhysioArt activity helps us to diminish the isolation by coronavirus pandemic".

\section{Acknowledgements}

The authors would like to thank the professors and post-graduate students for participating in and evaluating the artwork. We are thankful to all students and professionals who participated in this project, especially Bruno Maximiliano, Camille Gomes, Rebeca Lopes, Michelini Machado, Maria Jaene Alves, Girlene Silva, and Silvana Pampuch.

\section{Funding}

This work was financially supported by CAPES (88881.062209/2014-01), and CNPQ (447690/2014-0).

\section{Conflicts of Interest}

The authors declare no conflicts of interest regarding the publication of this paper.

\section{References}

Aird, W. C. (2011). Discovery of the Cardiovascular System: From Galen to William Harvey. Journal of Thrombosis and Haemostasis, 9, 118-129. https://doi.org/10.1111/j.1538-7836.2011.04312.x

Antunes, A., \& Monte, M. (1991). Eu Sei (Na Mira)-Mais album. EMI, Phonomotor. https://www.youtube.com/watch?v=YmVSj8T3D6U

Barreto, G., \& Oliveira, M. (2004). A arte secreta de Michelangelo: Uma lição de anatomia na Capela Sistina. ARX.

Bestetti, R. B., Restini, C. B. A., \& Couto, L. B. (2014). Development of Anatomic Physiologic Knowledge Regarding the Cardiovascular System: From Egyptians to Harvey. Arquivos Brasileiros de Cardiologia, 103, 538-541. https://doi.org/10.5935/abc.20140148

Braverman, I. M. (2011). To See or Not to See: How Visual Training Can Improve Observational Skills. Clinics in Dermatology, 29, 343-346. https://doi.org/10.1016/j.clindermatol.2010.08.001 
Campbell, J. I. (2014). Art and the Uncertainty of Medicine. JAMA, 312, 2337-2339. https://doi.org/10.1001/jama.2014.10773

Chi, X., Becker, B., Yu, Q., Willeit, P., Jiao, C., Huang, L., Solmi, M. et al. (2020). Prevalence and Psychosocial Correlates of Mental Health Outcomes among Chinese College Students during the Coronavirus Disease (COVID-19) Pandemic. Frontiers in Psychiatry, 11, 803. https://doi.org/10.3389/fpsyt.2020.00803

Chiang, M., Reid-Varley, W. B., \& Fan, X. (2019). Creative Art Therapy for Mental Illness. Psychiatry Research, 275, 129-136. https://doi.org/10.1016/j.psychres.2019.03.025

Courneya, C. A. (2018). Heartfelt Images: Learning Cardiac Science Artistically. Medical Humanities, 44, 20-27. https://doi.org/10.1136/medhum-2016-011140

Elmer, T., Mepham, K., \& Stadtfeld, C. (2020). Students under Lockdown: Comparisons of Students' Social Networks and Mental Health before and during the COVID-19 Crisis in Switzerland. PLOS ONE, 15, e0236337. https://doi.org/10.1371/journal.pone.0236337

Flôr, A. F. L., Fernandes Costa, F., Lima Garcia, J. M., Braga, V. A., \& Cruz, J. C. (2020). PhysioArt: A Teaching Tool to Motivate Students to Learn Physiology. Advances in Physiology Education, 44, 564-569. https://doi.org/10.1152/advan.00025.2020

Gabbe, M. (2016). Aristotle on the Metaphysics of Emotions. Apeiron, 49, 33-56. https://doi.org/10.1515/apeiron-2015-0014

Harvey, W., \& Willis, R. (1847). The Works of William Harvey, M.D. The Sydenham Society.

Haworth, J., Shik Song, J., \& Soo Song, J. (2016). Brain Divided. https://www.youtube.com/watch?v=JuyB7NO0EYY

Housen, A. C. (2002). Aesthetic Thought, Critical Thinking and Transfer. Arts and Learning Research, 18, 99-131.

Kahlo, F. (1939). The Two Fridas. https://mam.inba.gob.mx/coleccion-mam\#

Kaparounaki, C. K., Patsali, M. E., Mousa, D. P. V., Papadopoulou, E. V. K., Papadopoulou, K. K. K., \& Fountoulakis, K. N. (2020). University Students' Mental Health amidst the COVID-19 Quarantine in Greece. Psychiatry Research, 290, Article ID: 113111. https://doi.org/10.1016/j.psychres.2020.113111

Kush, V. (1978). Butterfly Apple. https://vladimirkush.com/butterfly-apple

Lazzeri, D., Al-Mousawi, A., \& Nicoli, F. (2019). Sandro Botticelli's Madonna of the Pomegranate: The Hidden Cardiac Anatomy. Interactive Cardiovascular and Thoracic Surgery, 28, 619-621. https://doi.org/10.1093/icvts/ivy321

Lomas, D. (2005). Painting the History of Cardiology. British Medical Journal, 331, 1533 1535. https://doi.org/10.1136/bmj.331.7531.1533

Matisse, H. (1947). Icarus (Icare) from Jazz. https://www.moma.org/collection/works/105386\#: :text=Inthefinaldecadesof,arranged themintolivelycompositions

Naghshineh, S., Hafler, J. P., Miller, A. R., Blanco, M. A., Lipsitz, S. R., Dubroff, R. P., Katz, J. T. et al. (2008). Formal Art Observation Training Improves Medical Students' Visual Diagnostic Skills. Journal of General Internal Medicine, 23, 991-997. https://doi.org/10.1007/s11606-008-0667-0

Odriozola-González, P., Planchuelo-Gómez, Á., Irurtia, M. J., \& de Luis-García, R. (2020). Psychological Effects of the COVID-19 Outbreak and Lockdown among Students and Workers of a Spanish University. Psychiatry Research, 290, Article ID: 113108. https://doi.org/10.1016/j.psychres.2020.113108 
Perry, M., Maffulli, N., Willson, S., \& Morrissey, D. (2011). The Effectiveness of Arts-Based Interventions in Medical Education: A Literature Review. Medical Education, 45, 141-148. https://doi.org/10.1111/j.1365-2923.2010.03848.x

Santos, I. P., Rosa, J. P. C., Ellwanger, J. H., Molz, P., Rosa, H. T., \& Campos, D. (2013). Michelangelo's Art on the Sistine Chapel Ceiling: Sacred Representation or Anatomy Lessons? Journal of Morphological Sciences, 30, 43-48.

Shapiro, J., Rucker, L., \& Beck, J. (2006). Training the Clinical Eye and Mind: Using the Arts to Develop Medical Students' Observational and Pattern Recognition Skills. Medical Education, 40, 263-268. https://doi.org/10.1111/j.1365-2929.2006.02389.x

Simonet, E. (1890). Anatomy of the Heart; and She Had a Heart! Or Autopsy. https://en.wikipedia.org/wiki/Museo_de_Málaga\#/media/File:Enrique_Simonet_-_La_ autopsia_1890.jpg

Tang, W., Hu, T., Hu, B., Jin, C., Wang, G., Xie, C., Xu, J. et al. (2020). Prevalence and Correlates of PTSD and Depressive Symptoms One Month after the Outbreak of the COVID-19 Epidemic in a Sample of Home-Quarantined Chinese University Students. Journal of Affective Disorders, 274, 1-7. https://doi.org/10.1016/j.jad.2020.05.009

Van Gogh, V. (1888). Bedroom in Arles. https://www.vangoghmuseum.nl/en/collection/s0047V1962

Van Gogh, V. (1889). The Starry Night. https://www.moma.org/collection/works/79802

Van Gogh, V. (1890a). Treurende oude man (“At Eternity's Gate”), mei. https://krollermuller.nl/vincent-van-gogh-treurende-oude-man-at-eternity-s-gate

Van Gogh, V. (1890b). Vase with Irises against a Yellow Background. https://www.vangoghmuseum.nl/en/collection/s0050V1962 